Portland State University

PDXScholar

1990

\title{
A study in the language acquisition styles of language delayed toddlers
}

Shelly Saunders

Portland State University

Follow this and additional works at: https://pdxscholar.library.pdx.edu/open_access_etds

Part of the Communication Commons, and the Linguistics Commons Let us know how access to this document benefits you.

\section{Recommended Citation}

Saunders, Shelly, "A study in the language acquisition styles of language delayed toddlers" (1990). Dissertations and Theses. Paper 4106.

https://doi.org/10.15760/etd.5990

This Thesis is brought to you for free and open access. It has been accepted for inclusion in Dissertations and Theses by an authorized administrator of PDXScholar. Please contact us if we can make this document more accessible: pdxscholar@pdx.edu. 
AN ABSTRACT OF THE THESIS OF Shelly Saunders for the Master of Science in Speech Communication presented March 14, 1990 .

Title: A Study in the Language Acquisition Styles of Language Delayed Toddlers.

APPROVED BY THE MEMBERS OF THE THESIS COMMITTEE:

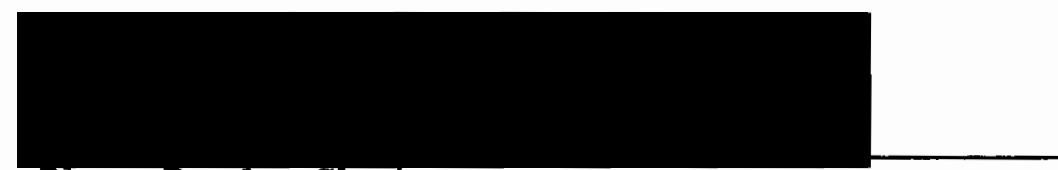

Rhea paul, chair

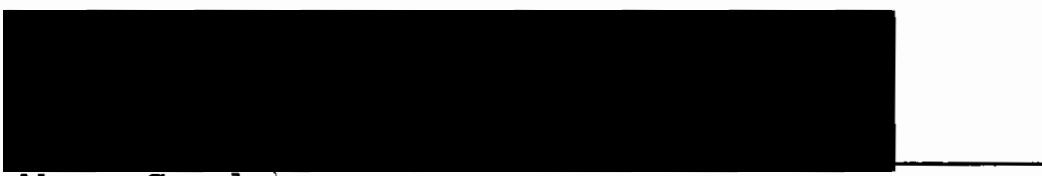

Mary Gordon

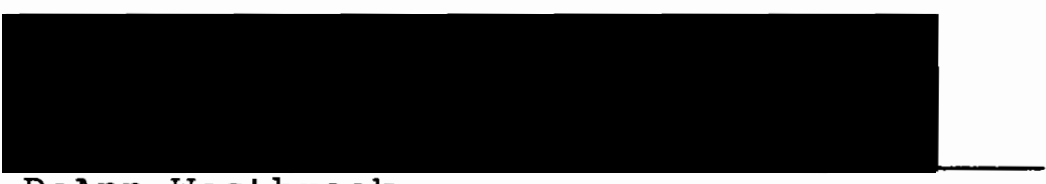

DeÂnn Westbrook

Most theories of language acquisition assume that children learn language along the same course of development, i.e., naming, to telegraphic speech, to grammar, with the only difference being the rate at which language is acquired. Nelson, in her 1973 study of normal toddlers and in her subsequent studies in 1975 and 1981, Bloom, Lightbrown, and Hood in 1975, Bates and Mcwhinney in 1987, and Horgan in 1981 determined that all children do not acquire language along the same developmental course. Rather, there are some children whose early childhood language is comprised primarily 
of names for objects and people, a referential style. Then there are those children whose early childhood language is comprised of primarily verbs, adjectives, function words, and expressive phrases such as "bye-bye," an expressive language style.

Nelson, in her 1981 study, also found that referential speakers, until age 30 to 36 months, have significantly larger vocabularies than do expressive speakers.

Bates and McWhinney in 1987 claimed that most children are neither expressive or referential. Rather they fall somewhere in the middle, using both strategies. They further concluded that it is the children at the extreme ends of the referential/expressive continuum that may exhibit qualitatively different language styles.

The purpose of the present study was to determine if language delayed toddlers, 18 to 30 months of age, were at one end of the referential/expressive continuum. It was this researcher's hypothesis that due to the restricted vocabulary of children who use an expressive language style, that the delayed toddlers would tend to be more expressive speakers.

A vocabulary checklist was completed by parents and evaluated in terms of the percent of referential words in the total vocabulary. Those scoring $40 \%$ and below were classified as expressive. Those scoring $60 \%$ and above were classified referential and those falling between $41 \%$ and $59 \%$ were classified as neither referential or expressive. 
The normal group consisted of 26 toddlers between 18 and 30 months, and the delayed group consisted of 27 toddlers of the same age group. The criteria for the delayed group was as follows: (1) less than 10 words at 18 to 23 months, and (2) less than 50 words or no two-word combinations at 24 to 34 months.

A Chi Square test on each individual group, normal and delayed, and a multinomial probability test comparing the two groups showed significant differences in the use of language styles within the two groups, and a significantly different distribution of styles. In other words, more toddlers than would be expected by chance choose a referential strategy, and fewer choose an expressive strategy for both the normal and delayed groups. Also, when comparing the two groups it was found that significantly more normal toddlers than delayed toddlers used a referential strategy, and significantly fewer used an expressive or no specific strategy. 
A STUDY IN THE LANGUAGE ACQUISITION STYLES

OF LANGUAGE DELAYED TODDLERS

by

SHELLY SAUNDERS

A thesis submitted in partial fulfillment of the requirements for the degree of

\author{
MASTER OF SCIENCE \\ in \\ SPEECH COMMUNICATION
}

Portland State University

1990 
TO THE OFFICE OF GRADUATE STUDIES:

The members of the committee approve the thesis of She11y Saunders presented March 14, 1990.
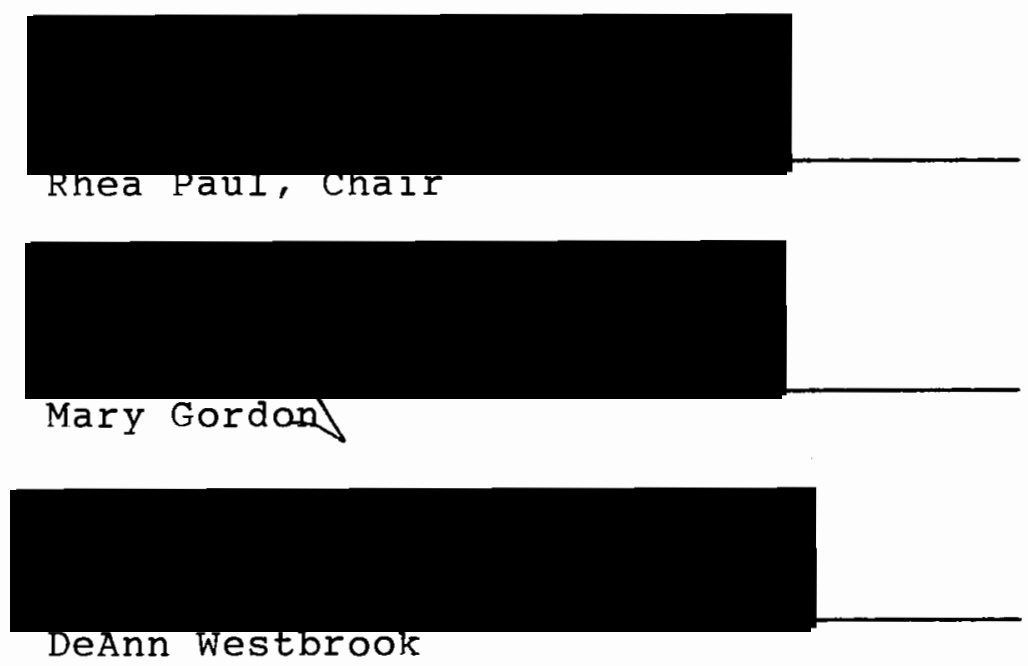

APPROVED :

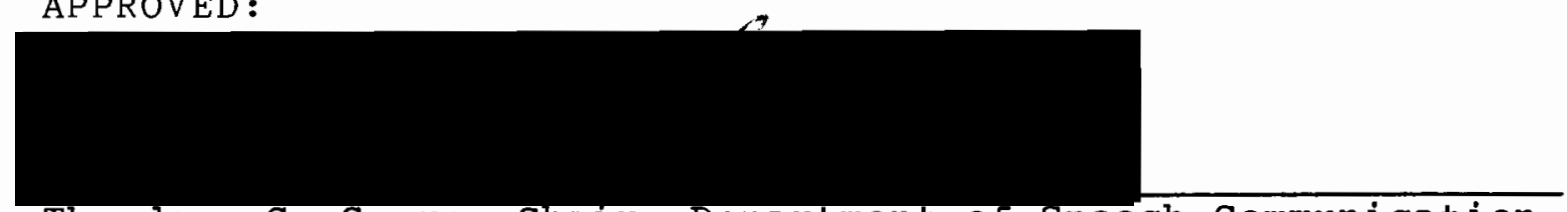

Theodore G. Grove, Chair, Department of Speech Communication

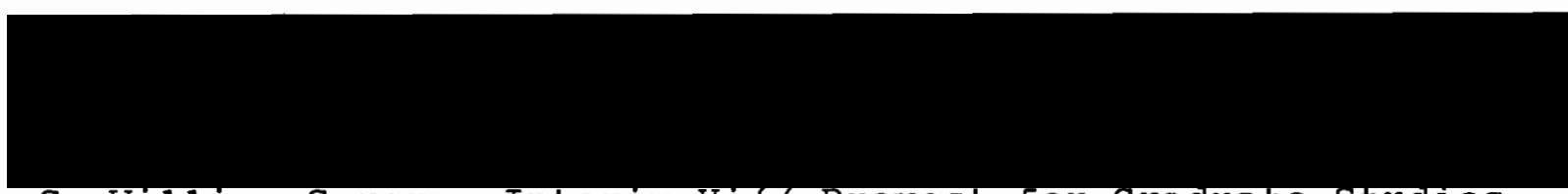

C. Wiliam Savery, Interim Vice Provost for Graduate Studies and Research 
TABLE OF CONTENTS

PAGE

LIST OF TABLES . . . . . . . . . . . . . . . . . V v

CHAPTER

I INTRODUCTION . . . . . . . . . . . . . 1

Purpose . . . . . . . . . . . 1

Research Hypothesis . . . . . . . 2

Nu11 Hypothesis . . . . . . . . . 2

Definition of Terms . . . . . . . . 3

II REVIEW OF THE LITERATURE . . . . . . . . . 4

Language Acquisition Theories . . . . 4

Individual Differences in Acquisition

Styles ............ 5

III METHODS . . . . . . . . . . . . 10

Subjects . . . . . . . . . . 10

Instrumentation and Procedures . . . . 11

Reliability . . . . . . . . . 13

Data Analysis . . . . . . . . . 13

IV RESULTS AND DISCUSSION . . . . . . . . . 15

Results . . . . . . . . . . . 15

Discussion . . . . . . . . . . . 18

$\mathrm{V}$ SUMMARY AND IMPLICATIONS . . . . . . . . 23

Summary . . . . . . . . . . 23 
CHAPTER

PAGE

Implications

Research

Clinical

REFERENCES

APPENDIX

A VOCABUlary CHECKList . . . . . . . . . . . . . 29

B COVER LETTER . . . . . . . . . . . . . . . . 32

C REFERENTIAL AND EXPRESSIVE FORM CLASSES • • • 34 


\section{LIST OF TABLES}

TABLE

PAGE

I Chi Square Test Results for Normal and

Delayed Groups • • • • • • . • • • • .

II Chi Square Test of Multinomial Probabilities

Between Normal and Delayed Groups . . . .

II Means, Standard Deviations, and Ranges of

Proportion of Referential Words for

Normal and Delayed Groups . . . . . . .

IV Percentage of Toddlers in the Three

Categories for Normal and Delayed

Groups . • • • • • . . • • • • • • • 
CHAPTER I

\section{INTRODUCTION}

To this date most research done in the area of individual differences in language acquisition has been focused on those children with normal language development. This thesis in language learning styles will examine individual differences in children with expressive language delays.

In the 1960's the literature in language acquisition gave the impression that all children acquire language along the same developmental course: naming, to telegraphic speech, to grammar (Bates and McWhinney, 1987). However, beginning in the 1970 's researchers such as Nelson (1973) and Bloom, Lightbrown, and Hood (1975), began researching individual differences in the way children acquire language. Nelson, in 1973, found that children use different strategies to acquire language: a referential or naming strategy, versus an expressive or prosocial strategy. Bloom, Lightbrown, and Hood (1975) reported similar findings in that some children use predominantly nouns in their early language acquisition while others use mainly pronouns. These two groups were termed "nominal" and "pronominal." Those children who were termed referential or nominal speakers were reported to have a significantly larger vocabulary than those children who were defined as expressive speakers. 
PURPOSE

The purpose of this study is to determine if language delayed toddlers tend to use one strategy in preference to the other in acquiring language. That is, do language delayed toddlers prefer a referential strategy using predominantly naming words, or do they choose an expressive strategy using predominantly social interactive language, such as: need, want, and bye-bye. Secondly, the study will ask whether the distribution of strategy use in the delayed group differs from that in the normal group. The findings of this study could be helpful in determining treatment goals for expressive language delayed toddlers. That is, if it is found, as expected, that expressive language delayed toddlers tend toward a more expressive style of acquiring language, remediation could focus on developing naming skilis.

\section{RESEARCH HYPOTHESIS}

Significantly more toddlers in the language delayed group will use an expressive language acquisition style than do todders in the normal group.

\section{NULL HYPOTHESIS}

Neither the expressive language delayed or normal toddlers will show a preference for either a referential or an expressive language acquisition style. 
1. Expressive language delayed toddlers--refers to those toddlers with limited expressive vocabularies who show: (1) less than 10 words at 18 to 23 months, and (2) less than 50 words or no two-word combinations at 24 to 34 months.

2. Expressive style--productive vocabularies of toddlers that contain at least $60 \%$ pronouns, verbs, adjectives, function words, and expressive phrases such as "bye-bye."

3. Normal lanquage toddlers--refers to those toddlers with expressive vocabularies of (1) more than 10 words at 18 to 23 months, and (2) more than 50 words and use of two-word combinations at 24 to 34 months.

4. Referential style--productive vocabularies of toddlers that contain at least $60 \%$ referential words, names of objects and people.

5. Toddlers--children between 18 and 24 months of age. 
CHAPTER II

REVIEW OF THE LITERATURE

\section{LANGUAGE ACQUISITION THEORIES}

There have been four major theories of language acquisition predominate in the literature in this field. The first is the behaviorist approach to language acquisition which proposes that language is learned through classical and/or operant conditioning (Skinner, 1957; Watson, 1924). The second approach, the linguistic approach, assumes that language has a structure somewhat independent of language use. Chomsky claimed that these structures consist of a finite set of rules shared by all speakers of a language (Gleason, 1989), and that they are learned through innate biological processes.

The primary assumption of the third approach, cognitive interactionist, is that language development is based on the sequence of language development. This theory is basea on Piaget's theory of cognitive development (Piaget, 1926). An example of this is that a child must reach the object permanence stage in order to be able to hold an object's image in mind before the words that represent objects can be acquired. A fourth approach is the social interactionist theory of language acquisition. The idea behind this theory is that 
young children first use language as a social tool for interacting with their parents. Those that support this approach propose that the child cues the parent as to the appropriate language needed for language development (Gleason, 1989). In other words, the young child needs efficient social communication at each stage of language development in order to improve his/her language skills (Gleason, 1989).

\section{INDIVIDUAL DIFFERENCES IN ACQUISITION STYLES}

Although these theories offer differing explanations of how language is acquired, they assume that all children go through basically the same course of development, i.e., naming, to telegraphic speech, to grammar, with the only difference being the rate at which acquisition takes place (Horgan, 1981).

In 1973 Nelson began to study the possibility that there are individual differences in the way children acquire language. In her study of 18 children from 12 to 30 months of age, Nelson used the first 50 words acquired by each child and assigned these words to form classes (nominals, action words, modifiers, personal-social terms, and function words )

Briefly, what she found was that all children learn names or labels for familiar people, animals, foods, toys, vehicles, and household objects. However, there was a difference in the proportion of nominals in their vocabularies. Ten of the subjects had early lexicons that were dominated by 
words for objects. These subjects were labeled "referential" speakers. Eight of these subjects had a higher proportion of pronouns, modifiers, function words, and personal-social items, "stop it," "go away," etc. These children were labeled "expressive" speakers.

Nelson, in this 1973 study, argued that these differences were due to different hypotheses about how language is used. The referential group was learning language to talk about and categorize the objects in their environment. The expressive group was more socially oriented and was acquiring the means to talk about themselves and others.

Other studies conducted by Nelson (1975a, 1975b, 1981), Bloom, Lightbrown, and Hood (1975), Bates and McWhinney (1987), and Horgan (1981), support Nelson's 1973 findings that children seem to acquire language through different strategies and that these differences fall consistently along these referential/expressive Iines.

In Nelson's 1975 study on individual differences in early semantic and syntactic development, it appeared that the strategy of language acquisition used by a child was related to the child's theory of the function of language as reported in her 1973 study. In this same study it was also found that expressive speakers acquired language by repeating many whole phrases and sentences. It appeared that they acquired language at a slower rate than did the referential speakers. They used more personal and impersonal pronouns and their early lexicons were oriented toward 
social interaction (Nelson, 1975a). The referential speakers on the other hand, had significantly larger vocabularies by age 2 years and used more agents in their early lexicons. It appeared that their early language was oriented toward the action of people (Nelson, 1975a).

In another study, Nelson (1975b) found that referential speakers clearly went from one-word to two-word phrases whereas expressive speakers tended to use imitative multiword phrases from the very beginning. In 1981 Nelson again reported that referential speakers used a significantly larger vocabulary than did the expressive speakers until 24 to 30 months of age. At this age the two groups' vocabularies were approaching the same size. It was also found in the 1981 study that expressive speakers used mainly pronouns in sentences while the referential speakers used mostly nouns in their first word combinations (Ne1son, 1981).

In looking at pronoun use in early language acquisition Bloom et al. (1975) also found individual differences in acquisition styles. In this study it was found that two of the four subjects used a nominal style, phrases or sentences composed of mostiy nouns and other content words, and the other two subjects were said to use a pronominal style, phrases in which the same meaning was conveyed using nonspecific pronominal forms or pronouns. However, by the time the four children in this study reached a mean length of utterance (MLU) of 2.5, the differences in noun and pronoun use had disappeared (Bloom et al., 1975). 
There appear to be several characteristics that 1 ink the referential and nominal and the expressive and pronominal styles together (Bates and McWhinney, 1987). Expressive and pronominal styles are associated with a greater tendency to imitate at both the word level and the sentence level. Also, the articulation of both the expressive and pronominal groups is usually imprecise and difficult to understand (Bates and McWhinney, 1987). As for the nominal and referential speakers they tend to emphasize the use of nouns and the development of noun phrases (Horgan, 1981). They also characteristically go from one-word to two-word phrases followed by sentences. In contrast, the pronominal/expressive speaker uses imitative multiword phrases and sentences from the beginning with poor articulation ski11s.

In summary, nominal/referential speakers are characterized as follows: larger vocabularies until 30 to 36 months, predominantly noun lexicons, clear articulation, definite one-word and two-word stages followed by sentences. The pronominal/expressive speakers are characterized by: higher proportion of pronouns in sentences, poorer articulation, and a higher proportion of verbs, modifiers, function words, adjectives, and expressive phrases.

Although there appear to be individual differences in language acquisition styles, it should be noted that both referential and expressive styles fall on a continuum rather than a dichotomy with most children falling somewhere in the middle, using both strategies, and that the two styles of 
language acquisition do not seem to result in different language outcomes by the age of $2-1 / 2$ or 3 years. It is the children at the extreme ends of the continuum that may reflect qualitatively different acquisition strategies (Bates and McWhinney, 1987). This study will ask whether children with late acquisition of expressive language represent one end of this continuum. 
CHAPTER III

METHODS

SUBJECTS

The subjects were comprised of a total of 53 children, 26 with normal expressive language skills and 27 with delayed expressive language skilis.

The subjects were obtained from three sources for a larger study being conducted at Portland State University.

1. All parents of children 18-30 months of age seeking well-baby checkups, within a 5-month period, for their children at three local pediatric clinics were asked to complete a questionnaire describing the child's expressive vocabulary (see Appendix A).

2. Subjects were also obtained from a radio broadcast describing the study and giving a phone number parents could call. These parents also completed the vocabulary questionnaire.

3. Parents responded to a newspaper article in The Oregonian requesting subjects for a larger study being conducted at Portland State University. These parents also completed the vocabulary questionnaire. Criteria for eligibility in the language delayed group were as follows: 
a. 18-23 months: use of less than 10 words, by parent report.

b. 24-34 months: use of less than 50 words or no two-word combinations, on the parent questionnaire.

All other subjects with larger vocabularies at the above age levels were considered candidates for the normal group. All delayed subjects were invited to participate in the study. Normal subjects were chosen from the pool of candidates so that the two groups were matched for age, sex, race, and socioeconomic status. All subjects, normal and delayed, passed a hearing screening in a sound field at $25 \mathrm{~dB}$ and showed cognitive ability within normal range on the Bayley Scales of Infant Development (Bayley, 1969). A11 subjects appeared to have normal neurological function based on a behavioral observation.

This researcher remained blind as to the diagnostic group in which each subject was placed until both gathering and analyzing of the data were completed.

Parent permission forms were distributed and explained by researchers at the subject's first evaluation session at Portland State University (see Appendix B).

\section{INSTRUMENTATION AND PROCEDURES}

The instrument used to assess expressive vocabulary size and assign subjects to groups was the Language Development Survey (Rescorla, 1989) (see Appendix A). This 
checklist has been used to identify expressive language delay in toddlers and is reported to have excellent reliability and validity (Rescorla, 1989). It consists of 350 words divided into various semantic categories.

The checklist was completed by each subject's parent at the initial evaluation at Portland State University following these instructions printed on the form: "Circle each word your child says. Don't include words your child can understand but not say. It's okay to count words that are not pronounced clearly. If your child speaks a foreign language, please check off the English version of the words he uses." (See Appendix A.) (No speakers of a foreign language were included in this study.)

The words on the list were names for familiar foods, toys, animals, body parts, places, people, clothes, vehicles, personal items, outdoor and household items, action words, modifiers, and others such as "A,B,C," "bye-bye," etc. (For a complete 1 ist of the words please see Appendix A.) From the checklist, words reported for each subject were assigned by this researcher to form classes according to Nelson's 1973 criteria (nominals, action words, modifiers, function words, and personal-social items). A1so, following Nelson's rules, nominals were assigned to the category of referential words, while all other form classes were assigned to the category of expressive words (Appendix C).

The percentage of referential words used by each subject was calculated by dividing the number of referential 
words reported on the Lanquage Development Survey by the total vocabulary size reported there. Those subjects with $60 \%$ or more nominal words were assigned to the referential group and those with $40 \%$ or fewer nominal words were assigned to the expressive group. Those whose use of nominals fell between $41 \%$ and $59 \%$ were assigned as "neither referential or expressive." The $60 \%$ and $40 \%$ cutoffs were chosen for the purpose of distinguishing those children who show some marked preference from those who use both referential and expressive vocabulary with similar frequency. This latter procedure was not done in Nelson's 1973 study.

\section{RELIABILITY}

Interjudge reliability was used to assess the reliability of assigning words to the referential and expressive categories on the vocabulary checklist. A second judge was trained in assigning words to form classes according to those used in Nelson's 1973 study. Ten percent of the checklist were randomly selected and the words independently assigned to class forms by a trained graduate student. The interjudge reliability was then calculated by means of percent of agreement. The interjudge reliability, using this procedure, was $100 \%$.

\section{DATA ANALYSIS}

Data from the vocabulary checklist were analyzed using a Chi Square test (Shapiro and Sardy, 1985) to decide 
whether the proportion of the two language styles, referential and expressive, were used with equal frequency by toddlers in the language delayed group. A Chi square test of multinomial probabilities was used to decide if the two groups differed significantly in the proportion of subjects choosing each strategy. 


\section{RESULTS AND DISCUSSION}

\section{RESULTS}

The data were analyzed to see if significantly more expressive language delayed toddlers used an expressive language learning style than those toddlers in the normal group. The following results were obtained.

A Chi Square test was used to determine if there was a significant difference in the number of subjects using a referential as opposed to expressive language learning style for both normal and delayed groups (see Table I).

TABLE I

CHI SQUARE TEST RESULTS FOR NORMAL AND DELAYED GROUPS

\begin{tabular}{l|ccc|c}
\hline \multirow{2}{*}{ Subjects } & $\begin{array}{c}\text { Style } \\
\text { Referen- } \\
\text { tial }\end{array}$ & $\begin{array}{c}\text { Expres- } \\
\text { sive }\end{array}$ & Neither & Chi Square \\
\cline { 2 - 5 } Normal & 25 & 0 & 1 & 47.58 \\
Delayed & 15 & 5 & 7 & 6.29 \\
\hline
\end{tabular}

$(\mathrm{K}-1) \mathrm{df}=2$. With 2 df a Chi square value greater than 5.99 is required at the .05 level of significance to reject the null hypothesis. 
The Chi Square value computed from the data for the delayed group was 6.29 with 2 degrees of freedom (Table I). This exceeds the critical value of 5.99 using an alpha level of .05. Thus, more delayed toddlers than would be expected by chance chose a referential strategy, and fewer chose an expressive strategy. The same results were found for the normal group. However, when the two groups were compared, a Chi square test of multinomial probabilities revealed that the distribution of strategy use in the two groups was significantly different. In other words, significantly more normal toddlers than delayed toddlers used a referential strategy, and significantly fewer used an expressive or no specific strategy. This distribution resulted in a Chi Square value of 11.98 with 2 degrees of freedom, with a critical value of 5.99 at an alpha level of .05 (see Table II).

TABLE II

CHI SQUARE TEST OF MULTINOMIAL PROBABILITIES BETWEEN NORMAL AND DELAYED GROUPS

\begin{tabular}{l|ccc|c}
\hline \multirow{2}{*}{ Subjects } & $\begin{array}{c}\text { Style } \\
\text { Referen- } \\
\text { tial }\end{array}$ & $\begin{array}{c}\text { Expres- } \\
\text { sive }\end{array}$ & Neither & Chi Square \\
\hline Normal & 25 & 0 & 1 & 11.98 \\
Delayed & 15 & 5 & 7 & \\
\hline
\end{tabular}

$(\mathrm{K}-1) \mathrm{df}=2$. With 2 df a Chi square value greater than 5.99 is required at the .05 level of significance to reject the null hypothesis. 
Since there is a significant difference between the two groups, this researcher examined the kinds of discrepancies between the means, standard deviations, range, and percentage of subjects using the expressive style, referential style, or neither style.

By examining Tables III and IV, it is clear that the delayed group shows greater diversity in vocabulary acquisition style. The delayed group had a range of 0 to $100 \%$ referential words while the normal group had a range of $58 \%$ to $85 \%$ referential words, indicating that the delayed group has more subjects at the extreme ends of the referential/ expressive continuum. Bates and McWhinney (1987) implied that it is those children at the extreme ends of the referential/expressive continuum that may have qualitatively different language styles. This may apply to some of the subjects in the delayed group.

\section{TABLE III}

MEANS, STANDARD DEVIATIONS, AND RANGES OF PROPORTION OF REFERENTIAL WORDS FOR NORMAL AND DELAYED GROUPS

\begin{tabular}{lccc}
\hline Subjects & $M$ & SD & Range (\%) \\
\hline Normal & 65.50 & 6.55 & $58-87$ \\
Delayed & 55.85 & 21.40 & $0-100$ \\
\hline
\end{tabular}


TABLE IV

PERCENTAGE OF TODDLERS IN THE THREE CATEGORIES FOR NORMAL AND DELAYED GROUPS

\begin{tabular}{lccc}
\hline \hline Subjects & Referential & Expressive & Neither \\
\hline Normal & 96 & 0 & 4 \\
Delayed & 56 & 19 & 25 \\
\hline
\end{tabular}

When looking at the percentages of referential and expressive speakers and those that adopt neither strategy, the delayed group again appears to be more diversified. The normal group contained $96 \%$ referential speakers while only $56 \%$ of the delayed group were referential speakers. On the other hand, $19 \%$ of the delayed group were expressive speakers while $0 \%$ of the normal group used an expressive language style (Table III). Also, the normal group had only $4 \%$ who were neither referential or expressive while the delayed group had $25 \%$ of the subjects in the neither category.

\section{DISCUSSION}

It may be that toddlers in the delayed group have problems acquiring language because their strategy for learning language is in conflict with their theory of the function of language. Nelson, in her 1973 study, found that those children in the referential group were learning language to talk about and categorize the objects in their environment, while the expressive group was more socially oriented and was acquiring a means to talk about themselves and others. In 
other words, a language delayed toddler may think that language has a more social function, to control the environment, but is learning names for objects, people, etc. If this toddler thinks that language is used for social purposes rather than categorizing the objects in their environment as the referential speakers appear to be doing, then the strategy of naming objects and people may not have significant meaning for this toddler. They may need to learn new vocabulary in a more social context such as, "I want the ball." The referential learner may need to learn new vocabulary by having words put into categories such as animals, toys, people, etc.

A source of variance in the results concerning the delayed group may be in the definition of language delayed for the 24 month and over group. Under the definition in this study, language delayed subjects may have vocabularies the same size as subjects in the normal group, but were classified as delayed because they used no two-word phrases. Since it is known that, for the most part, expressive speakers have smaller vocabularies than do the referential speakers (Nelson, 1981), there may be a greater number of expressive speakers in the delayed group if, for the 24 month and older subjects, language delay was defined in terms of limited vocabulary only and not two-word phrases. By using this criterion, all those termed delayed would be in the delayed group based on the same criteria rather than having a 50-word or less vocabulary for some and not for others. 
In examining the delayed group, 7 subjects had vocabularies over the 50-word cutoff for establishing language delay, but were classified as delayed because they used no two-word utterances. Al1 7 of these subjects were referential speakers. None of the delayed subjects who were categorized in the expresssive or neither categories had vocabularies over 50 words. If the criterion for language delay was based on vocabulary size only for the 24 month and older category there would have been 8 referential, 5 expressive, and 7 neither toddlers in the delayed group, instead of 15 referential, 5 expressive, and 7 in the neither category. This would have resulted in a chi value of .72 which is less than the critical value of 5.99 at the .05 alpha level with 2 degrees of freedom. These results show that there is not a significant difference in the language learning styles of the toddlers in the delayed group and would therefore change that outcome of the study.

A strength in the design, and hence the results, of this study is the procedure for distinguishing the referential speakers from the expressive speakers. It will be recalled that the purpose of this study was to establish whether or not language delayed toddlers tend to use an expressive language style. It was not clear in Nelson's 1973, 1975, or 1981 studies on individual differences of normal children 12 to 30 months of age what parameters were used to determine whether a subject was referential or expressive. This researcher felt that in order for the 
results of the current study to be valid, those subjects who had vocabularies close to $50 \%$ referential and $50 \%$ expressive should not be considered in either category. To clearly identify referential as opposed to expressive speakers, those with referential vocabularies of $40 \%$ and below were classified as expressive and those with $60 \%$ and above were classified as referential. These parameters should have eliminated any variance that may have been caused by classifying subjects in the wrong category. In using these parameters, those assigned to either category truly represent expressive or referential language styles.

In reviewing the method of obtaining the subjects' vocabulary size and content, this researcher feels that by using a vocabulary checklist instead of a vocabulary diary as Nelson (1973) did may have lead to some incorrect, under or over, reporting of the vocabularies of the subjects. There may have been words that the parents did not report on the checklist because they did not remember them at the time they were filling out the checklist. Another concern is that a parent may have over-reported the number of words their child has in his/her vocabulary. For example, it is possible to see a word on the checklist that may have been used once or twice by a child but is not used consistently in the correct context and is reported as a vocabulary word. It is this researcher's opinion that a word must be used consistently in the correct context before it can be considered part of a child's vocabulary. However, it should be noted that 
Rescorla (1989) reports validity of the Language Development Survey to be excellent. This type of reporting error could have been alleviated if the checklist instructions were "to circle any words your child uses correctly on a consistent basis" rather than "circle any word your child says." Many toddlers say a word once or twice and then do not use the word again for a long time. It seems to this researcher that such words are not truly part of their expressive vocabularies. 
CHAPTER V

SUMMARY AND IMPLICATIONS

SUMMARY

Most theories of language acquisition assume that children learn language along the same course of development, i.e., naming, to telegraphic speech, to grammar with the only difference being the rate at which language is acquired (Horgan, 1981).

Nelson, in her 1973 study of normal toddlers and in her subsequent studies, 1975a, 1975b, and 1981, Bloom, Lightbrown, and Hood (1975), Bates and McWhinney (1987), and Horgan (1981) determined that all children do not acquire language along the same developmental course. Rather, there are some chidren whose early childhood language is comprised primarily of names for objects and people, a referential style. Then there are those children whose early childhood language is comprised of primarily verbs, adjectives, function words, and expressive phrases such as "bye-bye," an expressive style.

Nelson in her 1981 study also found that referential speakers until age 30 to 36 months have significantly larger vocabularies than do expressive speakers.

Bates and McWhinney (1987) claimed that most children are neither expressive or referential. Rather they fall 
somewhere in the middle using both strategies. They further concluded that it is the children at the extreme ends of the referential/expressive continuum that may exhibit qualitatively different language styles.

The purpose of the present study was to determine if language delayed toddlers, 18 to 30 months of age, were at one end of the referential/expressive continuum. It was this researcher's hypothesis that due to the restricted vocabulary of children who use an expressive language style, that the delayed toddlers would tend to be more expressive speakers.

A vocabulary checklist was completed by parents and evaluated in terms of the percent of referential words of the total vocabulary. Those scoring $40 \%$ and below were classified as expressive. Those scoring $60 \%$ and above were classified as referential and those falling between $41 \%$ and $59 \%$ were classified as neither referential or expressive.

The normal group consisted of 26 toddlers between 18 to 30 months and the delayed group consisted of 27 toddlers of the same age group. The criteria for the delayed group was as follows: (1) less than 10 words at 18 to 23 months, and (2) less than 50 words or no two-word combinations at 24 to 34 months.

A Chi square test on each individual group, normal and delayed, and a multinomial probability test comparing the two groups showed significant differences in the use of 1anguage styles within the two groups, and a significantly different distribution of styles. In other words, more toddlers 
than would be expected by chance choose a referential strategy for both the normal and delayed groups. Also, when comparing the two groups it was found that significantly more normal toddlers than delayed toddlers used a referential strategy, and significantly fewer used an expressive or no specific strategy.

\section{IMPLICATIONS}

\section{$\underline{\text { Research }}$}

Further research in the area of language delayed children and individual differences is needed. A follow-up study on these same language delayed toddlers is recommended to establish if any of these toddlers are actually late bloomers as opposed to chronically language delayed. It would be interesting to know if there was a significant difference in language styles in those subjects who remain language delayed as 4 and 5 year olds. If there were a significant difference for this group it would suggest that an evaluation of a child's language style, referential or expressive, could provide important diagnostic information.

\section{Clinical}

From the present study it appears that examining a language delayed child's vocabulary in terms of referential or expressive style in addition to the traditional analysis of quantity of expressive vocabulary could be helpful in the diagnostic process. 
It is this researcher's feeling that the more information speech and language pathologists have about language delayed children the better they can design treatment programs. For example, if a child is hard of hearing a clinician teaches strategies for that child to learn language through lip reading, using contextual cues, etc. In other words, the best strategy for teaching language to a hearing impaired child is the one that best suits the individual child, not the same strategy for every child. The same should be true for the language delayed toddler. Even though this study does not indicate the type of treatment plan that would best suit these delayed toddlers it is this researcher's opinion that by utilizing the child's strategy for learning language, referential or expressive, you could change the context of the treatment program to best suit each toddler. A social context could be used for the expressive language learner and a naming or categorizing context could be used with the toddler who uses a referential style to learn language. 
REFERENCES

Bates, E. and McWhinney, B. (1987). Competition, variation, and language learning. In Brian MCWhinney (ed.), Mechanisms of language acquisition, pp. 182-185. Hillsdale, NJ: Lawrence Erlbaum Associates.

Bayley, N. (1969). Scales of infant development. New York: Psychological Corporation.

Bloom, L., Lightbrown, P., and Hood, I. (1975). Structures and variations in child language. Monographs of the Society for Research in Child Development, $40(2)$.

Gleason, J. (1989). The development of language. Columbus, $\mathrm{OH}$ : Charles E. Merrill.

Horgan, D. (1981). Rate of language acquisition and noun emphasis. Journal of Psycholinguistic Research, $10(6)$.

Nelson, K. (1973). Strategies in learning how to talk. Monographs of the Society for Research in Child Development, $\underline{38}(1,2)$.

(1975a). Individual differences in early semantic and syntactic development. Annals of the New York Academy of Science, 263, $132-139$.

(1975b). The nominal shift in semantic development. Cognitive Psychology, 7, 461-469.

(1981). Individual differences in language deve1opment: Implications for development and language. Developmental Psychology, 17, 170-187.

Piaget, J. (1926). The language and thought of the child. New York: Harcourt Brace Jovanovich.

Rescorla, L. (1989). The language development survey: A screening tool for delayed language in toddlers. Journal of Speech and Hearing Disorders, 54, 587-599.

Schapiro, M. and Sardy, H. (1985). A research primer for the social and behavioral sciences. New York: Academic Press. 
Skinner, B. F. (1957). Verbal Behavior. Englewood Cliffs, NJ : Prentice-Hall.

Watson, J. (1924). Behaviorism. Chicago: University of Chicago. 
APPENDIX A

VOCABULARY CHECKLIST 
APPENDIX A

\section{VOCABULARY CHECKIIST}

Please circle each word your child says. Don't include words your child can understand but not say. It's ok to count words that aren't pronounced clearly. If your child speaks a foreign language, please check off English versions of the words he uses.

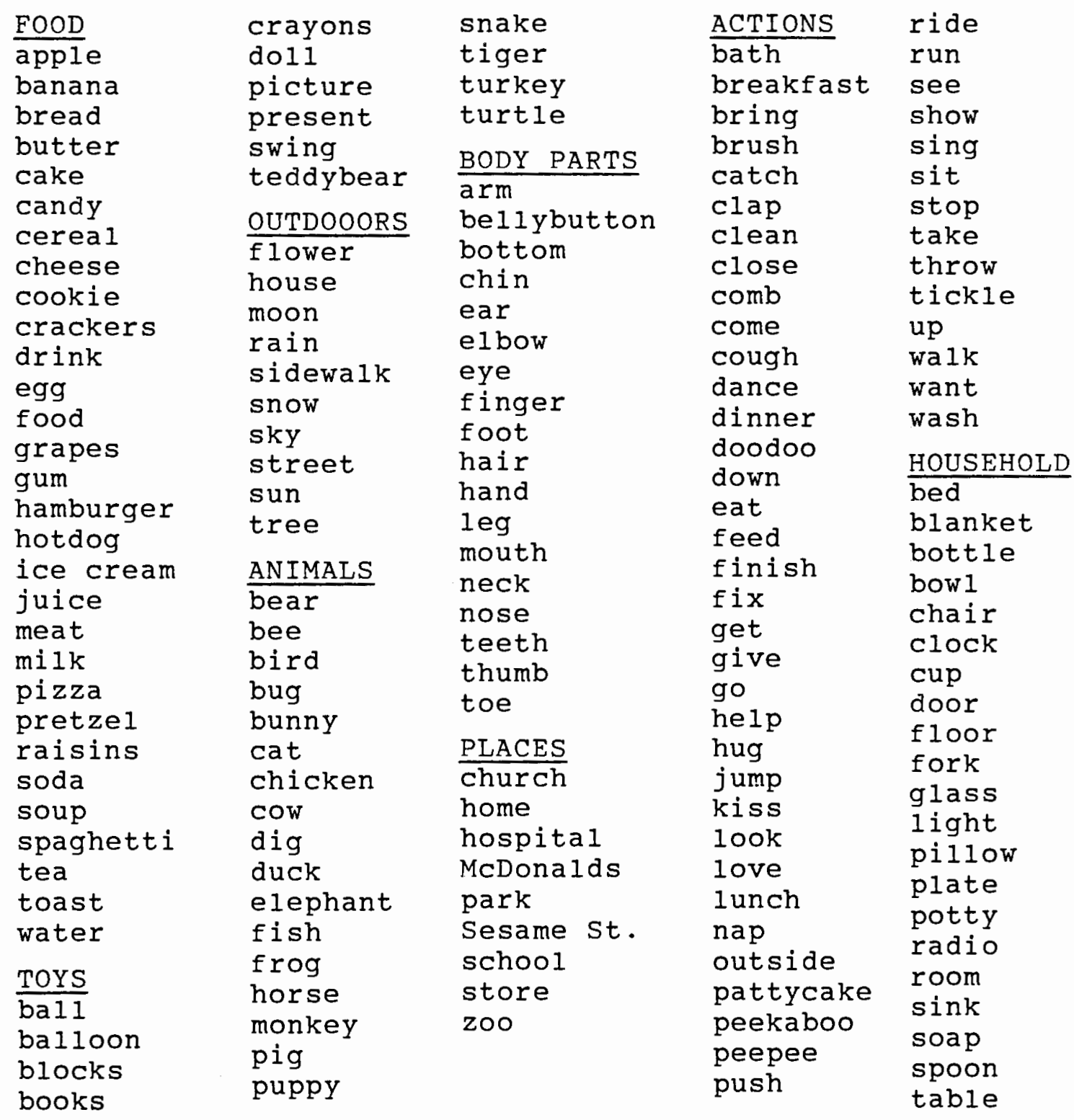




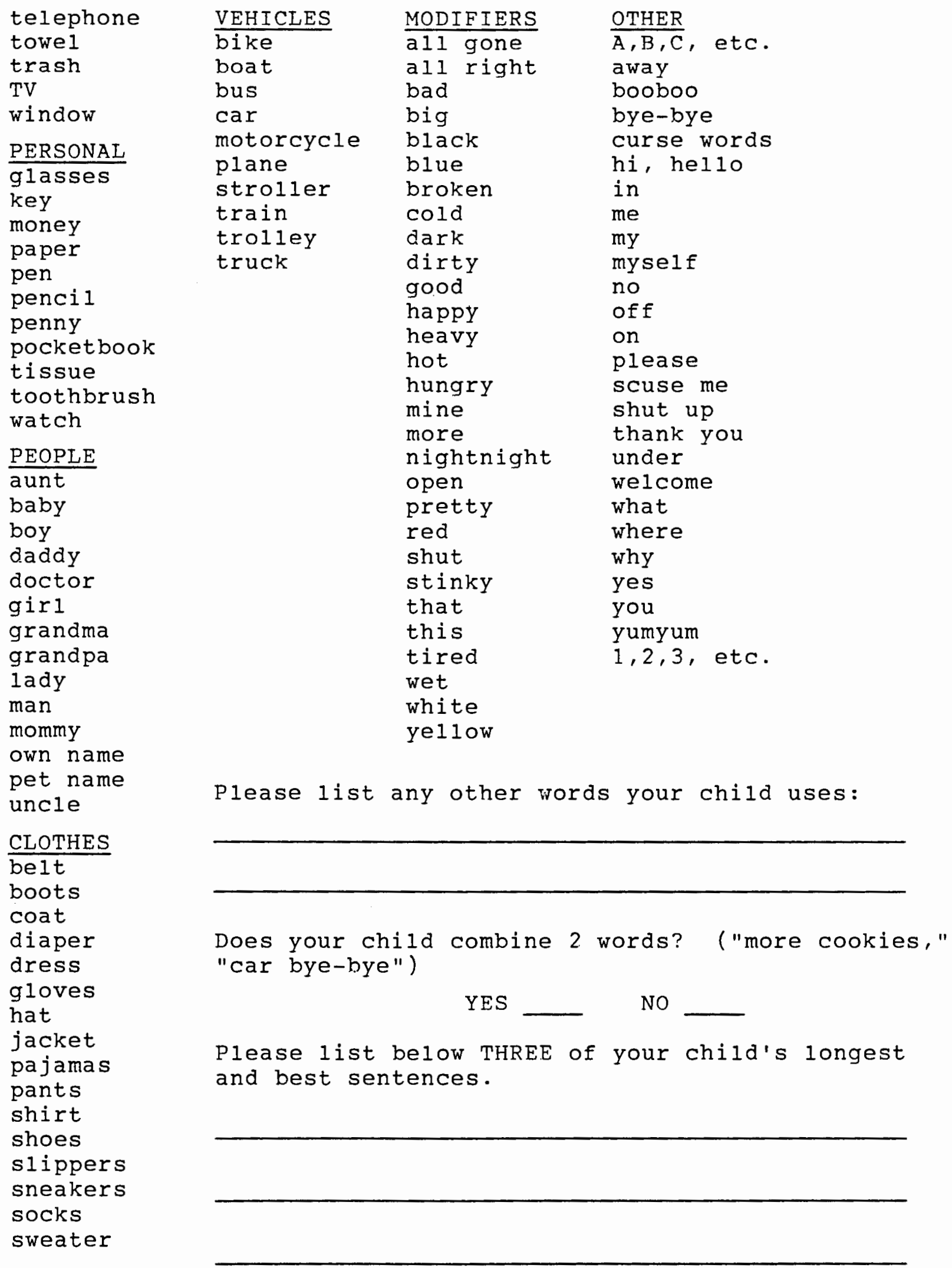


APPENDTX B

COVER LETTER 


\section{APPENDIX B}

COVER LETTER

Dear Parents,

We are trying to learn more about at what age children begin speaking, and what kinds of words they use when they start to talk. We would appreciate it greatly if you would answer the following questions and return this form to the nurse before you leave the office. Your cooperation in this study is voluntary and if you choose not to complete the questionnaire it will in no way affect the treatment you receive at Kaiser Permanente, at Portland State University, or anywhere else. If you choose to fill out the questionnaire, I would appreciate your including your phone number so that I may contact you in case I have a question.

We would like to study a few children in greater depth, as we11; If you would be interested in this later part of the study, please indicate so at the bottom of the questionnaire and give your name, address, and phone number. Again, your cooperation is completely voluntary. If you have any questions about the study, or about your child's speech, please do not hesitate to call me at Portland state University at 229-3142.

Thank you in advance for your help.

Yours,

Rhea Paul, Ph.D.

Assistant Professor

Encl. 
APPENDIX C

REFERENTIAL AND EXPRESSIVE FORM CLASSES 


\begin{abstract}
APPENDIX C
REFERENTIAL AND EXPRESSIVE FORM CLASSES
\end{abstract}

REFERENTIAL

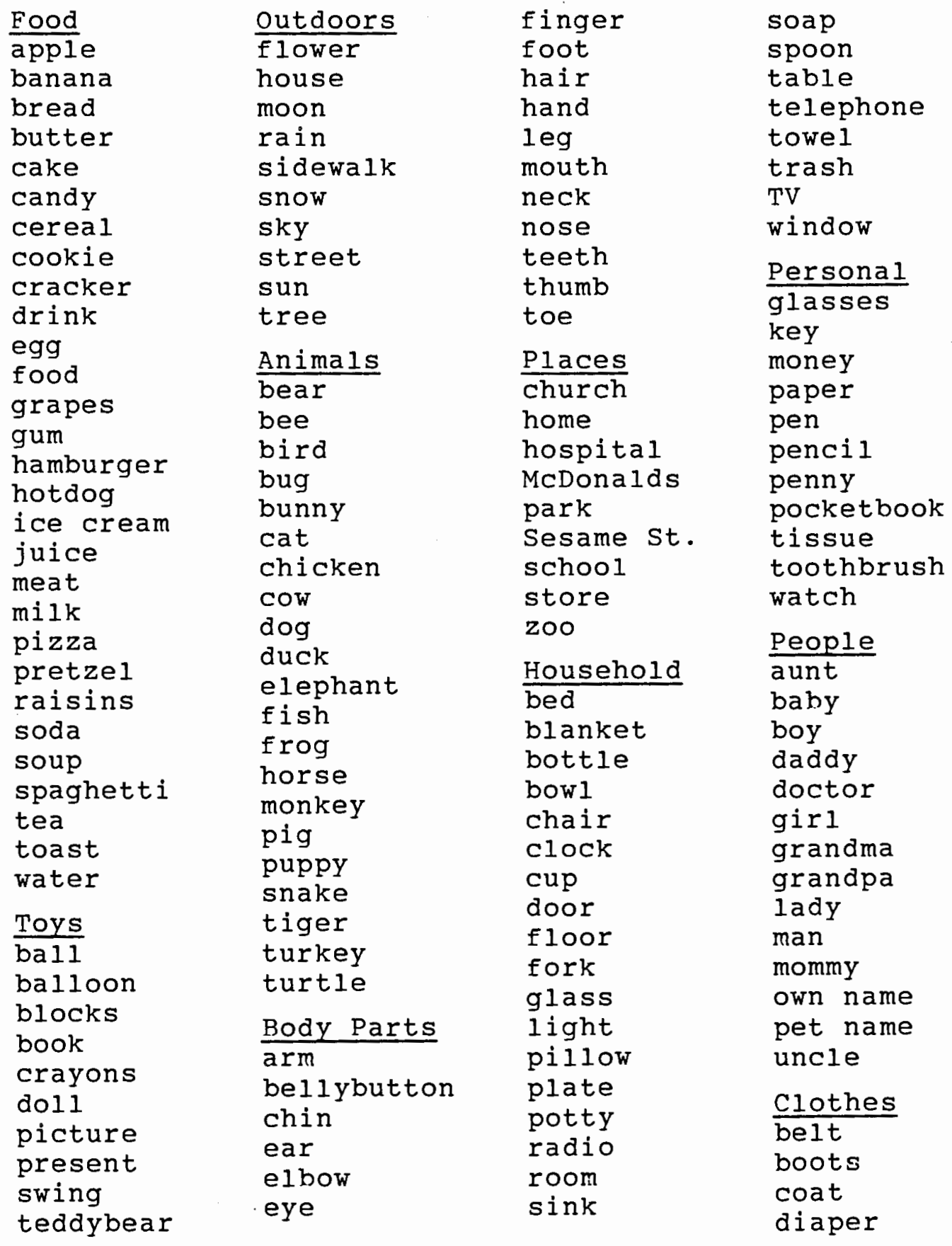


REFERENTIAL (cont.)

dress
gloves
hat
jacket
pajamas
pants
shirt
shoes
slippers
sneakers
socks
sweater
vehicles
bike
boat
bus
car
motorcycle
plane
stroller
train
trolley
truck

EXPRESSTVE

\begin{tabular}{|c|c|}
\hline$\frac{\text { Actions }}{\text { bath }}$ & Modifiers \\
\hline $\begin{array}{l}\text { bath } \\
\text { breakfast }\end{array}$ & $\begin{array}{ll}\text { all gone } & \text { right } \\
\text { al1 }\end{array}$ \\
\hline bring & bad \\
\hline brush & big \\
\hline catch & black \\
\hline clap & blue \\
\hline clean & broken \\
\hline comb & cold \\
\hline close & dark \\
\hline come & dirty \\
\hline cough & good \\
\hline dance & happy \\
\hline dinner & heavy \\
\hline $\begin{array}{l}\text { doodoo } \\
\text { down }\end{array}$ & hot \\
\hline $\begin{array}{l}\text { down } \\
\text { eat }\end{array}$ & $\begin{array}{l}\text { hungry } \\
\text { mine }\end{array}$ \\
\hline feed & more \\
\hline Einish & open \\
\hline fix & pretty \\
\hline get & red \\
\hline give & shut \\
\hline $\begin{array}{l}\text { go } \\
\text { help }\end{array}$ & $\begin{array}{l}\text { stinky } \\
\text { tired }\end{array}$ \\
\hline hug & wet \\
\hline jump & white \\
\hline kiss & ye11ow \\
\hline look & Pronouns \\
\hline love & me \\
\hline lunch & my \\
\hline $\begin{array}{l}\text { nap } \\
\text { outside }\end{array}$ & myself \\
\hline pattycake & $\begin{array}{l}\text { that } \\
\text { this }\end{array}$ \\
\hline $\begin{array}{l}\text { peekaboo } \\
\text { peepee }\end{array}$ & you \\
\hline push & Other \\
\hline ride & $A, B, C$, etc. \\
\hline run & away \\
\hline see & booboo \\
\hline show & bye-bye \\
\hline $\begin{array}{l}\text { sing } \\
\text { sit }\end{array}$ & $\begin{array}{l}\text { curse words } \\
\text { hi, hel10 }\end{array}$ \\
\hline stop & in \\
\hline take & nightnight \\
\hline $\begin{array}{l}\text { throw } \\
\text { tickle }\end{array}$ & $\begin{array}{l}\text { no } \\
\text { off }\end{array}$ \\
\hline up & on \\
\hline walk & please \\
\hline want & scuse me \\
\hline
\end{tabular}


EXPRESSIVE (cont.)

shutup

thank you

under

welcome

where

why

yes

yumyum

$1,2,3$, etc.

Other words as noted by parents:

Referential

Two-word combinations:
Expressive

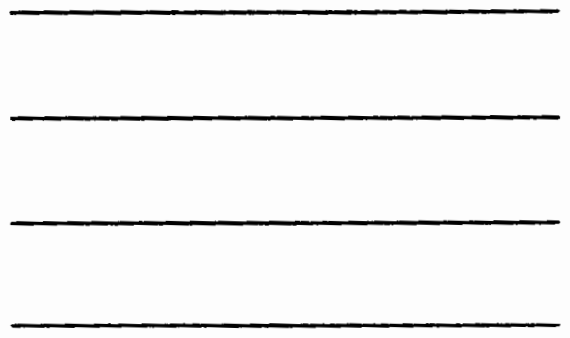

